\title{
EFICIÊNCIA DA COBERTURA MORTA NA RETENÇÃO DE UMIDADE NO SOLO
}

\author{
Djeson Mateus Alves da Costa \\ Professor do Departamento de Formação de Professores, Centro Federal de Educação \\ Tecnológica do Rio Grande do Norte. Av. Sem. Salgado Filho, 1553, CEP: 59015-000, \\ Natal (RN). E-mail: djeson@,cefetrn.br \\ Henio Normando de Souza Melo \\ Professor do Departamento de Engenharia Química, Universidade Federal do Rio Grande \\ do Norte. Campus Universitário, CEP: 59000-000, Natal (RN). E-mail: henio@eq.ufrn.br
}

\section{Sebastião Ribeiro Ferreira}

Professor do Departamento de Engenharia Química, Universidade Federal do Rio Grande do Norte. Campus Universitário, CEP: 59000-000, Natal (RN). E-mail: ferreira@eq.ufrn.br

\section{RESUMO}

O presente trabalho teve por objetivo monitorar as condições meteorológicas nos ambientes interior e exterior de uma casa de vegetação, construída em terreno pertencente ao CEFET-RN. Através dos registros das medidas da temperatura e umidade relativa do ar e da temperatura da superfície do solo, nos dois ambientes, avaliou-se a eficiência do uso da cobertura morta na retenção de umidade no solo e diminuição na temperatura na superfície do solo. Foi também determinada a taxa de evaporação nesses ambientes a partir da medida da perda de massa de água em mini-tanque de evaporação. O monitoramento desses parâmetros foi realizado no período compreendido entre 04/11 e 11/12/2005. O uso de proteção do substrato com folhas secas proporcionou redução significativa na taxa de evaporação da água do solo $(\mathrm{p}<0,01)$.

Palavra chave: Casa de vegetação, evaporação e umidade.

\section{EFFICIENCY OF THE MULCH ON SOIL HUMIDITY RETENTION}

\section{SUMMARY}

This work had the goal of monitoring the internal and external weather conditions of a greenhouse at CEFET/RN school, Brazil. The experiment was carried out to evaluate the efficiency of mulch in retaining the soil humidity, and decreasing the temperature on the soil surface through the measuring records of temperature and relative humidity in both environments. Moreover, the rate of evaporation inside and outside the greenhouse was determined by the measurement of the loss of water mass in Class A evaporation pans. The monitoring for these parameters took place from November 4 to December 11, 2005. The use of the protection for the soil with dry leaves showed a reduction on the rate of the soil evapotranspiration $(\mathrm{p}<0,01)$.

Key words: Greenhouse, evaporation and humidity. 


\section{EFICIÊNCIA DA COBERTURA MORTA NA RETENÇÃO DE UMIDADE NO SOLO}

\section{INTRODUÇÃO}

O uso de casa de vegetação para o cultivo de plantas de pequeno porte aumentou bastante no Brasil nos últimos anos, principalmente nas regiões Sul e Sudeste. Estima-se que essa área já atinja aproximadamente $1.000 \mathrm{ha}$, os quais são utilizados para o cultivo e a produção de plantas ornamentais, hortaliças e mudas das mais variadas espécies (Oliveira, 1995).

A cobertura plástica da casa de vegetação provoca alteração de parâmetros como temperatura do ar e do solo, umidade relativa do ar, vento, balanço de radiação e energia e, conseqüentemente, evapotranspiração (Galvani et al., 1998). O uso de filme plástico afeta as condições internas da casa de vegetação diminuindo a demanda evaporativa em função da diminuição da radiação solar e da velocidade do vento (Martins et al., 1999).

A diferença entre a evapotranspiração interna e externa da casa de vegetação varia de acordo com as condições meteorológicas. Em geral, a evapotranspiração no interior da casa de vegetação fica em torno de 60 a $80 \%$ daquela verificada no exterior (Montero et al., 1985). Farias et al. (1994) verificaram que a evapotranspiração de referência (ETo) no interior da casa de vegetação foi sempre menor, ficando entre 45 e $77 \%$ da verificada na parte externa. Braga \& Klar (2000) observaram que os valores da ETo foram 84,71 e $79,79 \%$ para as casas de vegetação orientadas na direção leste-oeste e norte-sul, respectivamente, em relação à ETo fora das mesmas.

Tanaka \& Genta (1982) observaram que o aumento da temperatura, no interior de ambiente fechado, proporcionava acréscimo conteúdo de umidade relativa do ar e, essa variação apresentava comportamento exponencial.

A irrigação é um sistema de manejo que adiciona água ao solo, e esta ao receber energia radiante, oriunda do sol, aumenta sua energia cinética ocasionando a sua evaporação. Segundo Klocke (2004), a taxa de evaporação de água do solo é tanto maior quanto mais úmida estiver sua superfície. Estando essa superfície seca a taxa de evaporação será controlada pelas propriedades do solo.

Um sistema de irrigação que utiliza água de má qualidade, em termos de concentração salina, deve adotar manejo adequado para evitar alta taxa de evaporação de água da superfície do solo (Maas \& Grattan, 1999). Durante a evaporação ocorre a precipitação dos sais solúveis presentes na água, na superfície do solo. Esse fenômeno pode causar grandes prejuízos ao sistema produtivo, afetando o desenvolvimento das plantas e, em grau mais acentuado, provocando a esterilidade do solo (Scofield, 1935; Richards, 1974, Rhoades et al., 2000).

A proteção do solo com cobertura morta promove incrementos na produção das plantas, aumenta a água disponível no solo, fornece nutrientes essenciais às plantas (Cadavid et al., 1998), reduz a perda de água por evaporação resultando em maior crescimento do sistema radicular na camada superficial e reduz a flutuação da temperatura na superfície do solo (Gill et al., 1996). 
A cobertura do substrato além de protegê-lo contra a perda de umidade favorece, também, a formação de microclima úmido para o desenvolvimento dos primórdios, serve de reservatório de água para as plantas em crescimento, favorece o desenvolvimento de microorganismos benéficos à frutificação e diminui o surgimento de ervas daninhas (Stamets \& Chilton, 1983; Alves et al., 1995).

A escolha do tipo de cobertura morta deve levar em consideração sua capacidade de retenção de água, porosidade, microbiótica benéfica, servir como fonte de nutrientes para a cultura, $\mathrm{pH}$ adequado e estar livre de insetos, nematóides e microorganismos competidores (Stamets \& Chilton, 1983). Para Flegg et al. (1985), a camada de cobertura deve favorecer a formação do gradiente de concentração de $\mathrm{CO}_{2}$ e possuir composição de nutrientes diferenciada do substrato de cultivo.

Depois de incorporada ao solo, a camada de cobertura morta aumenta a capacidade de água disponível do solo, a qual é determinada pela diferença entre a quantidade de água à capacidade de campo e ao ponto de murcha permanente (Stewart, 1994). Dados da FAO apontam reduções de até $30 \%$ na taxa de evapotranspiração do solo quando submetido à proteção, comparado ao solo descoberto (Stanghellini, 1993).

O objetivo desse trabalho foi avaliar os efeitos da cobertura morta na retenção de umidade pelo solo e na redução da temperatura da superfície do solo em dois ambientes de cultivo, utilizando folhas secas como material de proteção.

\section{MATERIAIS E MÉTODOS}

Este trabalho foi conduzido nos meios interior e exterior de uma casa de vegetação, ambos construídos em terreno do Centro Federal de Educação Tecnológica do Rio Grande do Norte (CEFET-RN), na cidade de Natal-RN, situada nas coordenadas geográficas de $5^{\circ} 48^{\prime} 37,5^{\prime}$ " latitude sul e $35^{\circ} 12^{\prime} 14,4^{\prime}$ ' longitude oeste, numa altitude média de $57 \mathrm{~m}$, apresentando insolação média anual de $2800 \mathrm{~h}$, com incidência de $0,86 \mathrm{cal} / \mathrm{cm}^{2} \cdot \mathrm{min}^{-1}$ ou $600 \mathrm{~J} \cdot \mathrm{m}^{-2} \cdot \mathrm{s}^{-1}$ (FONTES NÃO CONVENCIONAIS DE ENERGIA, 1999). A classificação climática para a região, segundo Köppen (1948), é do tipo Bsh (clima seco com chuvas de inverno e quente).

\section{Características da área}

O experimento foi desenvolvido no período de 4/11/2005 a 11/12/2005 nos meios interno e externo de uma casa de vegetação, estando posicionada no sentido leste - oeste. A casa foi edificada com alicerce em estrutura de concreto armado, estrutura de sustentação e de cobertura com barra de ferro galvanizada, coberta e fechada lateralmente com tela plástica, com redutor de insolação de 50\%. As dimensões da casa de vegetação mediam 4,50 x 8,00 $\mathrm{m}$, com altura na parte central de $3,00 \mathrm{~m}$ e pé direito de $2,50 \mathrm{~m}$.

\section{Condução da pesquisa}

Foram utilizados seis vasos plásticos, sem dreno, com capacidade para $10 \mathrm{~kg}$ de solo. Em quatro desses vasos foram colocados $8 \mathrm{~kg}$ de solo agrícola e nos outros dois $8 \mathrm{~kg}$ de água $\left(\mathrm{CE}_{\mathrm{ES}}=0,145 \mathrm{dS} \cdot \mathrm{m}^{-1}\right)$. Em dois dos vasos com solo foi posta uma camada de cobertura morta (folhas secas de acácia), com espessura de $3 \mathrm{~cm}$, como forma de proteção do substrato. Três desses vasos - um com água, um com solo desprotegido e outro com solo 
protegido - foram colocados no interior da casa de vegetação e os outros três no exterior dela.

Após realizar a disposição e condicionamento dos vasos, nos dois meios, iniciou-se o monitoramento das condições meteorológicas através das medidas da temperatura e umidade relativa do ar, por meio de um higrômetro digital; da temperatura da superfície do solo com e sem proteção, por meio um termômetro digital; da massa de água evaporada do vaso de evaporação reduzido e da massa de água evaporada ou transpirada do solo com e sem proteção, por meio de uma balança digital.

As análises estatísticas foram realizadas utilizando-se o procedimento do teste de t-Student e ANOVA para a comparação das médias determinadas com os dados obtidos no interior e no exterior da casa de vegetação, aplicados aos diversos tratamentos.

\section{Características físico-químicas do solo}

$\mathrm{O}$ solo utilizado foi oriundo de um terreno de formação aluvial, o qual apresentou a seguinte granulometria: $36,1 \%$ de areia, $11,0 \%$ de argila e $52,9 \%$ de silte, tendo como classificação textural Franco-Siltoso.

As características físico-químicas do solo amostrado, utilizado no empacotamento dos vasos, constam na Tabela 1. As análises do solo foram feitas no Laboratório de Análises de Solo, Água e Planta da EMPARN (Empresa de Pesquisa Agropecuária do Rio Grande do Norte S/A, em Natal-RN).

O material foi recolhido numa propriedade rural, pertencente ao CEFET-RN, localizada às margens do Rio Açu, no município de Ipanguaçú-RN, distando $180 \mathrm{~km}$ da cidade de Natal, a 5'32'10,3" latitude sul e 3652'29,6" longitude oeste, numa altitude de $26 \mathrm{~m}$ em relação ao nível do mar. Essa área situa-se numa região de clima semi-árido, apresentando uma média anual para temperatura, umidade relativa do ar e precipitação de $27,5{ }^{0} \mathrm{C}, 70,0 \%$ e $600 \mathrm{~mm}$, respectivamente. A classificação climática de Köppen (1948), para essa região, é do tipo Bsh (seco com chuvas de inverno e quente).

Tabela 1: Características Físico-químicas do solo utilizado.

\begin{tabular}{|c|c|c|c|}
\hline Determinação & Teor & Determinação & Teor \\
\hline pH em água $(1: 2,5)$ & 7,50 & Potássio, mg.kg-1 & 389 \\
\hline Cálcio, cmol. $\mathrm{kg}^{-1}$ & 8,90 & Sódio, mg. $\mathrm{kg}^{-1}$ & 129 \\
\hline Magnésio, cmol.kg ${ }^{-1}$ & 3,50 & $\mathrm{CE}_{\mathrm{ES}}(1: 5), \mathrm{dS} \cdot \mathrm{m}^{-1}$ & 0,34 \\
\hline Alumínio, cmol. $\mathrm{kg}^{-1}$ & 0,00 & $\operatorname{PST}(\%)$ & 3,75 \\
\hline Hidrog. + Alum., cmol.kg-1 & 0,99 & Ret. água a 0,03 MPa (\%). & 14,6 \\
\hline Fósforo, $\mathrm{mg} \cdot \mathrm{kg}^{-1}$ & 175 & Densidade aparente, $\mathrm{g} . \mathrm{cm}^{-3}$ & 1,36 \\
\hline
\end{tabular}

CE $E_{\mathrm{ES}}$ : condutividade elétrica no extrato saturado; PST: porcentagem de sódio trocável.

De acordo com os dados da Tabela 1, observa-se que o solo amostrado apresenta-se como sendo não-salino e não sódico visto que possui $\mathrm{pH} \leq 8,5 ; \mathrm{CE} \leq 4 \mathrm{dS} \cdot \mathrm{m}^{-1}$ e PST $\leq 15$ (Richards, 1974; Bernardo, 1995). O solo estudado possui, ainda, vantagens de não 
apresentar problemas de acidez dispensando correção com uso de calcário $(\mathrm{pH}=7,5)$. Pode ser caracterizado como solo de baixa densidade $\left(1,00\right.$ a $\left.1,40 \mathrm{~g} . \mathrm{cm}^{-3}\right)$ o que induz a concluir que possui, relativamente, alto teor de matéria orgânica e/ou argila, favorecendo, portanto, a capacidade de retenção de umidade e uma boa porosidade (Raij, 1991).

\section{RESULTADOS E DISCUSSÕES}

\section{Monitoramento ambiental para caracterização dos meios interior e exterior à casa de vegetação}

O trabalho experimental teve início em 04/11/2005 através do monitoramento das condições meteorológicas no interior e exterior de uma casa de vegetação construída numa área experimental do CEFET-RN, em Natal. Essa atividade teve duração de 37 dias (encerrada em 11/12/2005) e teve como objetivos verificar a influência do meio condicionado na temperatura e umidade relativa do ar, na temperatura da superfície do solo e na retenção de umidade no solo com e sem uso de proteção.

\section{Temperatura e umidade relativa do ar}

As magnitudes térmicas do ar para o meio interior à casa de vegetação (TA1) foram consideradas elevadas, sendo a máxima e a mínima de $43,4{ }^{\circ} \mathrm{C}(11 \mathrm{~h})$ e $26,9{ }^{\circ} \mathrm{C}(17 \mathrm{~h})$, respectivamente. No meio exterior (TA2) os valores foram de $42,6{ }^{\circ} \mathrm{C}(14 \mathrm{~h})$, para a temperatura máxima, e de $26,9{ }^{\circ} \mathrm{C}(17 \mathrm{~h})$, para a temperatura mínima. Por conseguinte, tanto as máximas magnitude e amplitude térmicas no meio interior foram ligeiramente superiores que no meio exterior. Entretanto, as magnitudes mínimas para a temperatura do ar nos dois meios foram iguais.

Pela análise estatística, teste t-student ao nível de $5 \%$ de confiança, verificou-se que o uso da casa de vegetação influiu efetivamente para a redução da temperatura do ar, porém, não afetou significativamente os conteúdos da umidade relativa do ar, em todos os intervalos de tempo observados (7:00 às 17:00 h), resultados que corroboram com as observações de Galvani et al. (1998).

Para o período de menor insolação, início da manhã e final da tarde, as temperaturas do ar no interior da casa de vegetação foram sempre inferiores que as do exterior. Porém, uma inversão térmica para essa situação foi constatada para o intervalo do dia compreendido entre 11:00 e 13:00 h.

O aumento da temperatura do ar, no período das 7:00 às 12:00 h, ocasionou diminuição gradativa da umidade relativa do ar nos dois meios, interior (UR1) e exterior (UR2) à casa de vegetação, para o mesmo período de observação. Entretanto, para o intervalo de decréscimo na temperatura do ar, a partir das 12:00 até às 17:00 $\mathrm{h}$, ocorreu acréscimo na umidade relativa do ar nos dois ambientes citados, conforme apresentado no Figura 1. 


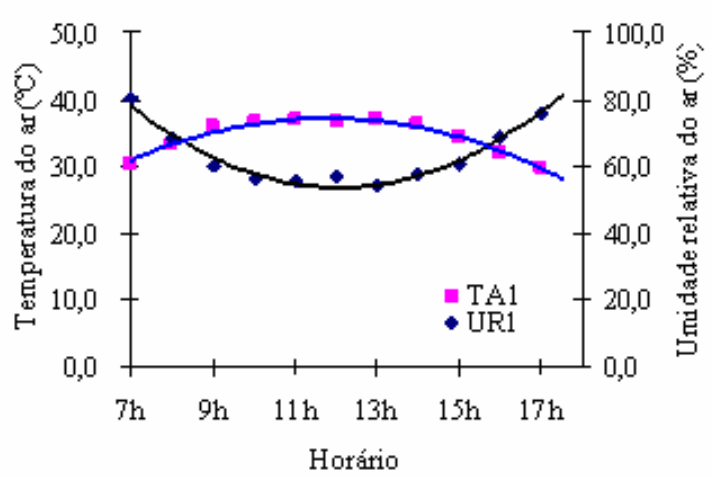

(a)

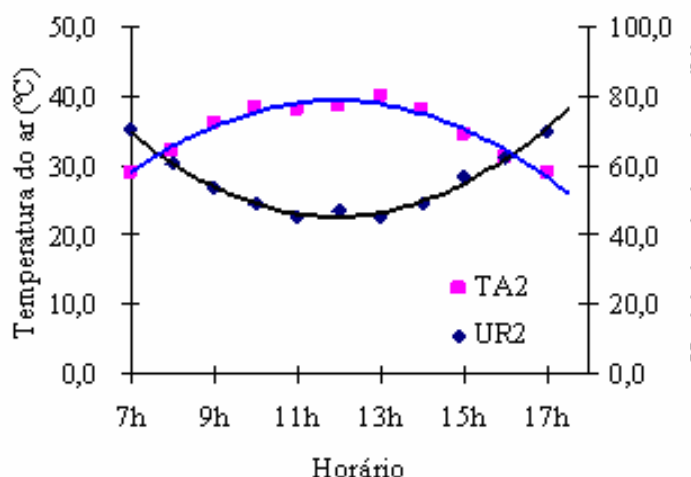

(b)

Figura 1: Variação média diária para a temperatura e umidade relativa do ar no interior (a) e no exterior (b) da casa de vegetação durante o período experimental.

Os valores máximos e mínimos para a umidade relativa do ar no interior e exterior da casa de vegetação, durante o período experimental foram $77 \%$ e $32 \% ; 79 \%$ e $31 \%$, respectivamente.

O fato do aumento da temperatura provocar diminuição na umidade relativa do ar justificase devido ao aumento da energia cinética das moléculas de água no estado de vapor. Nesse caso, com maior energia cinética, as moléculas passam a se deslocarem com maior velocidade ocupando ao mesmo tempo maior espaço em relação ao estado termodinâmico de menor temperatura. Com a dispersão das partículas de vapor de água o meio torna-se menos concentrado implicando numa diminuição da umidade relativa do ar.

A análise de regressão para a umidade relativa do ar, nos dois ambientes, apresentou decréscimo linear com o aumento da respectiva temperatura, como mostrado na Figura 2. Essas informações indicam que a predição da umidade relativa pode ser feita, com boa precisão, a partir do conhecimento da respectiva temperatura do ar.

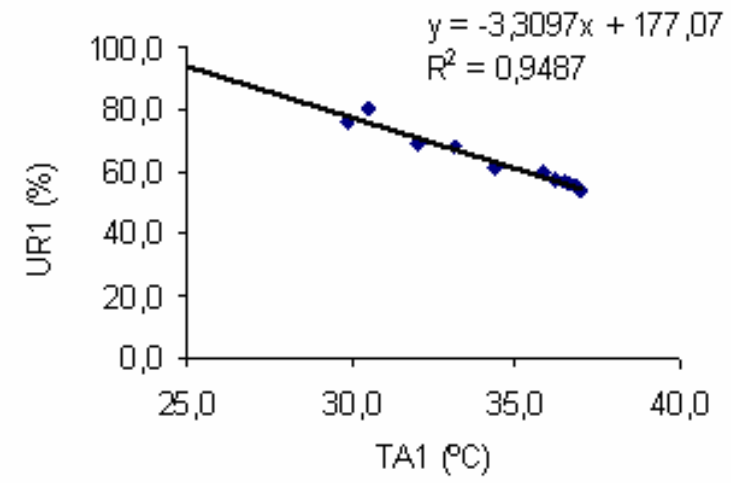

(a)

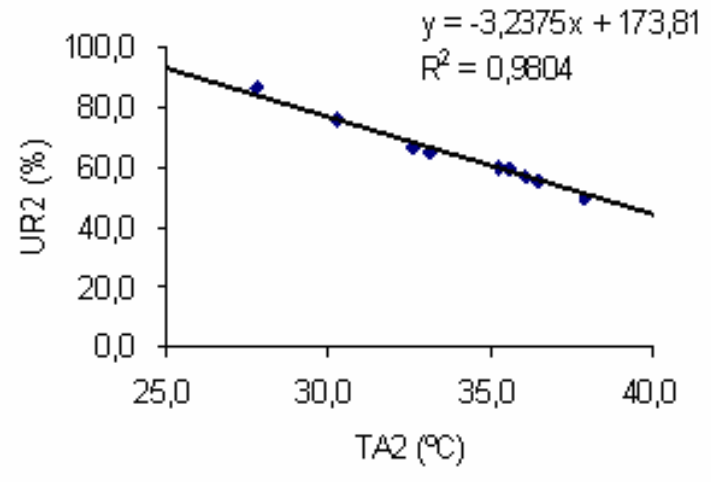

(b)

Figura 2: Relação entre as médias diárias da umidade relativa e da temperatura do ar no interior (a) e no exterior (b) da casa de vegetação durante o experimento.

A constatação de que a umidade relativa sofre influência direta da temperatura do ar corrobora com as conclusões de Tanaka \& Genta (1982), porém, esses autores mostraram 
que a umidade relativa varia exponencialmente com a temperatura do ar. Essa diferencia de comportamento deve-se às condições nas quais os experimentos foram conduzidos.

\section{Temperatura da superfície do solo}

Observou-se que as temperaturas médias na superfície do solo, para a maioria dos intervalos experimentados, quando protegido por cobertura morta, TS1-CC e TS2-CC, apresentaram valores sempre inferiores aos da superfície sem proteção, TS1-SC e TS2-SC, fato também observado por Gill et al. (1996). Esse comportamento foi verificado tanto para o solo acondicionado no interior quanto no exterior da casa de vegetação, conforme apresentado no Figura 3.

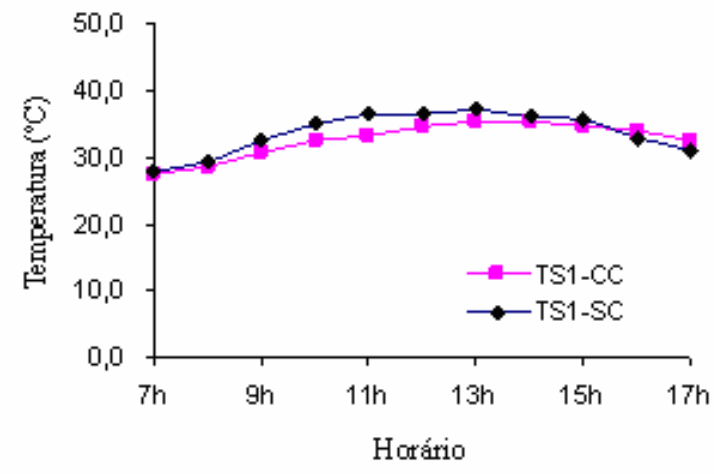

(a)

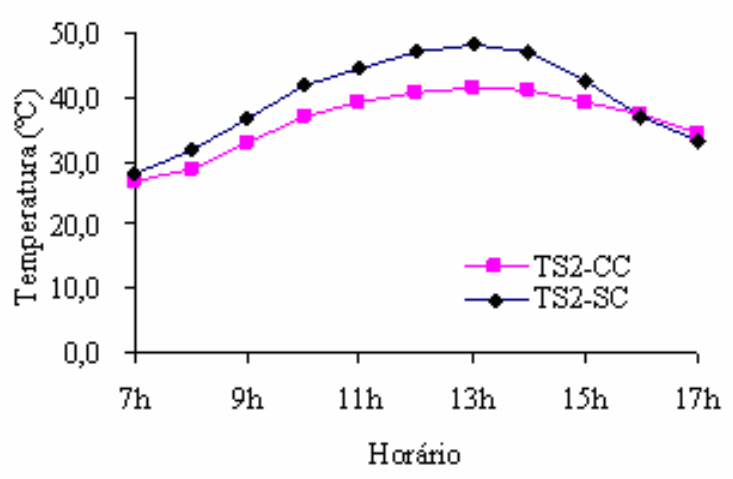

(b)

Figura 3: Temperatura média diária na superfície do solo nos meios interior (a) e exterior (b) à casa de vegetação, para o período de experimentado.

Na Figura 3 se evidencia, ainda, uma inversão térmica da temperatura média na superfície do solo protegido quando comparado ao não protegido, a partir das 15:00 h, fato esse diagnosticado nos dois ambientes experimentados. A presença da cobertura morta induziu uma maior retenção de umidade pelo solo (Cadavid et al., 1998) e, nesse caso, tendo a água um calor específico maior que o do solo seco, promoveu maior acúmulo de energia térmica no solo úmido. A dissipação de calor pelo solo umedecido, quando a temperatura começou a diminuir, após as 13:00 h, foi mais lenta que a do solo seco, consequentemente, a temperatura na superfície do substrato úmido tendeu a alcançar magnitudes mais elevadas que no solo com menos umidade, para esse intervalo do dia.

As menores magnitudes térmicas observadas em solo protegido, nos dois ambientes, não diferem significativamente $(\mathrm{p}<0,05)$, quando comparadas àquelas em solo descoberto. Por outro lado, o uso da casa de vegetação proporcionou reduções significativas $(p<0,01)$ na temperatura da superfície do solo, aspectos evidenciado, também, por Galvani et al. (1998). Não se observou interação significativa $(p<0,05)$ entre os tratamentos casa de vegetação x proteção do solo (Tabela 2). 
Tabela 2: Análise de variância para a temperatura média diária na superfície do solo, relativa aos intervalos experimentados.

\begin{tabular}{lcccc}
\hline Fonte de variação & G. L. & S. Q. & Q. M. & F \\
\hline Casa de vegetação & 1 & 55,44450 & 55,44450 & $39,2458^{\text {** }}$ \\
Proteção do solo & 1 & 0,42050 & 0,42050 & $0,2976^{\text {ns }}$ \\
Interação & 1 & 0,22050 & 0,22050 & $0,1564^{\text {ns }}$ \\
Resíduo & 16 & 22,60400 & 1,41275 & --- \\
Total & 19 & 78,68950 & --- & ---
\end{tabular}

G.L.: Grau de liberdade; S. Q.: soma dos quadrados; Q. M.: quadrado médio; F.: fator para análise de variância.

** significativo ao nível de $1 \%$ de probabilidade; ${ }^{\text {ns }}$ não significativo ao nível de $5 \%$ de probabilidade.

As amplitudes térmicas na superfície do solo no meio exterior à casa de vegetação apresentaram valores maiores que no outro meio. No interior da casa de vegetação a temperatura média na superfície do solo variou de $33,7^{\circ} \mathrm{C}$ (sem proteção) à $32,6{ }^{\circ} \mathrm{C}$ (com proteção), enquanto no exterior essa oscilação foi de $39,8{ }^{\circ} \mathrm{C}$ (sem proteção) à $36,3{ }^{\circ} \mathrm{C}$ (com proteção). A redução da amplitude e da magnitude da temperatura na superfície do solo imprime uma melhor homogeneidade desse parâmetro disponibilizando maior quantidade de água para as plantas. Essas observações estão coerentes com àquelas feitas por Gill et al. (1996).

\section{Taxas de evaporação em minitanques}

Através do teste t-student verificou-se que a taxa média diária de evaporação da água em minitanque, tipo Classe A, no interior da casa de vegetação foi significativamente $(p<0,01)$ reduzida quando comparada àquela no meio exterior; resultado que condiz com as observações de Martins et al. (1999). A evaporação total acumulada, no minitanque com água, durante o período experimentado foi igual a $136,66 \mathrm{~mm}$, no interior, e $188,29 \mathrm{~mm}$ no exterior da casa de vegetação. Nesse caso, constatou-se uma redução do potencial evaporativo igual a $27,42 \%$, quando comparando os dois ambientes. Esses dados estão de acordo com os obtidos por Montero et al. (1985), Farias et al. (1994) e Braga \& Klar (2000).

As análises estatísticas das taxas de evaporação da água em minitanques com solo com proteção e sem proteção, no interior e exterior da casa de vegetação estão apresentadas na Tabela 3. Os dados indicam que o uso da casa de vegetação e da cobertura morta proporcionaram, respectivamente, reduções significativas ao nível de 5 e $1 \%$, na taxa de evaporação diária. Não foi observada interação significativa, ao nível de $5 \%$, entre os tratamentos adotados. Reduções na perda de água do solo, por evaporação, devido ao uso de proteção foi, anteriormente, observada por Gill et al. (1996). 
Tabela 3: Análise de variância da taxa de evaporação diária da água em minitanque com solo com e sem proteção, dentro e fora da casa de vegetação.

\begin{tabular}{lcccc}
\hline Fonte de variação & G. L. & S. Q. & Q. M. & F \\
\hline Casa de vegetação & 1 & 1,53125 & 1,53125 & $6,5862^{*}$ \\
Proteção do solo & 1 & 7,78151 & 7,78151 & $33,4698^{* *}$ \\
Interação & 1 & 0,03781 & 0,03781 & $0,1626^{\text {ns }}$ \\
Resíduo & 28 & 6,50983 & 0,23249 & --- \\
Total & 31 & 15,86040 & --- & -- \\
\end{tabular}

G.L.: Grau de liberdade; S. Q.: soma dos quadrados; Q. M.: quadrado médio; F.: fator para análise de variância.

** significativo ao nível de $1 \%$ de probabilidade; * significativo ao nível de $5 \%$ de probabilidade; ${ }^{\text {ns }}$ não significativo ao nível de $5 \%$ de probabilidade.

O uso da casa de vegetação reduziu a taxa de evaporação, acumulada no período, de 72,61 para 60,69 $\mathrm{mm}$ (em solo protegido) e de 111,61 para 93,95 $\mathrm{mm}$ (em solo descoberto), representando, respectivamente, reduções de $16,42 \%$ e 5,82 \%. Por conseguinte, os redutores para as taxas de evaporação acumulada devido ao uso de proteção do solo, no meio interior e exterior à casa de vegetação foram, respectivamente, iguais a 35,40\% e $34,94 \%$. Esses resultados corroboram com os dados da FAO, segundo os quais o uso de proteção reduz em, aproximadamente, 30 \% a evapotranspiração do solo (Stanghellini, 1993).

Os resultados obtidos vislumbram a importância da prática do cultivo em casa de vegetação e o uso da cobertura morta, como forma de proteção do substrato. Por conseguinte, esses manejos favoreceram reduções na temperatura do solo, maior capacidade de retenção de umidade pelo substrato e, obviamente maior disponibilidade de água para as plantas, o que torna o habitat mais propício a uma boa germinação, desenvolvimento e produção de culturas agrícolas, conforme verificações feitas por Stanghellini (1993); Stewart (1994); Gill et al. (1996) e Cadavid et al. (1998).

\section{CONCLUSÕES}

O uso da casa de vegetação ocasionou aumento das magnitudes e amplitudes térmicas do ar, redução da umidade relativa e da evaporação em minitanque com água, quando comparado ao meio exterior.

O uso da cobertura morta reduziu as oscilações e amplitudes na temperatura da superfície do solo e na taxa de evapotranspiração, nos dois meios experimentados.

\section{LITERATURA CITADA}

ALVES, A.G.C.; COGO, N.P.; LEVIEN, R. Relações da erosão do solo com a persistência da cobertura vegetal morta. Revista Brasileira de Ciência do solo, Viçosa, v.19, n.1 p.127-132, 1995. 
BERNARDO, S. Manual de irrigação. Universidade Federal de Viçosa. Impr. Univ. $6^{\text {a }}$ Ed. Viçosa, 1995. 386p.

BRAGA, M.B.; KLAR, A.E. Evaporação e evapotranspiração de referência em campo e estufa orientadas nos sentidos norte-sul e leste-oeste. Irriga, Botucatu, v.5, n.3, p.222-228, 2000.

CADAVID, L.F.; EL-SHARKAWY, M.A.; ACOSTA, A.; SANCHES, T. Long-term effects of mulch, fertilization and tillage on cassava grown in sandy soils in northern Colombia. Field Crops Research, v.57, p.45-56, 1998.

FARIAS, J.R.B.; BERGAMASCHI, H.; MARTINS, S.R. Evapotranspiração no interior de estufas plásticas. Revista Brasileira de Agrometeorologia, Santa Maria, v.2, p.17-22, 1994.

FLEGG, P. B.; SPENCER, D. M.; WOOD, D. A. The Biology and Technology of the Cultivated of Mushroom. Chichester: John Wiley \& Sons, 1985, 347p.

FONTES NÃO CONVENCIONAIS DE ENERGIA. As Tecnologias Solar, Eólica e de Biomassa. $3^{\text {a }}$ Edição - Revista, Modificada e Ampliada- UFSC. 1999.

GALVANI, E.; DANTAS, R.T.; ESCOBEDO, J.F.; KLOSOWSKI, E.S. Parâmetros meteorológicos em cultura de alface (Lactuca sativa, L.) cultivada em casas de vegetação com orientações leste-oeste, norte-sul e condições externas. Revista Brasileira de Agrometeorologia, Santa Maria, v.6, n.2, p.157-63, 1998.

GILL, K.S.; GAJRI, P.R.; CHAUDHARY, M.R.; SINGH, B. Tillage, mulch, and irrigation effects on corn (Zea mays L.) in relation to evaporative demand. Soil Tillage Research, v.39, p.213-227, 1996.

KLOCKE, N.L. Crop Residue and Soil Water Evaporation. Water Resources Engineering. Kansas State University. Garden City, Kansas. 2004.

KÖPPEN, W. Climatologia Tradicional. Traduzido para o Espanhol por Pedro Henchiehs Pérez, 1948.

MAAS, E.V.; GRATTAN, S.R. Crop yields as affected by salinity. In: Skaggs, R.W.; van Schilfgrarde, J. (ed.) Agricultural drainage. Madison: ASA, CSSA, SSSA, 1999. p.55-108. Agronomy Monograph no 38.

MARTINS, S.R.; FERNANDES, H.S.; ASSIS, F.N. de; MENDEZ, M.E.G. Caracterização climática e manejo de ambientes protegidos: a experiência brasileira. Informe Agropecuário, Belo Horizonte, v.20, n.200/201, p.15-23, 1999.

MONTERO, J.I.; CASTILLA, N.; GUTIERREZ de RAVÉ, E.; BRETONES, F. Climate under plastic in the Almeria. Acta Horticulturae, The Hague, v.170, p.227-34, 1985.

OLIVEIRA, M.R.V. de. O emprego de casas de vegetação no Brasil: vantagens e desvantagens. Pesquisa Agropecuária Brasileira, Brasília, v.30, n.8, p.1049-60, 1995. 
RAIJ, B. van. Ferlilidade do Solo e Adubação. Associação Brasileira para Pesquisa da Potassa e do Fosfato/Editora Agronômica Ceres Ltda., Piracicaba/SP, 1991. 343p.

RHOADES, J.D.; Kandiah, A.; Mashali, A.M. Uso de águas salinas para produção agrícola. Campina Grande: UFPB. 2000, 117p. Estudos da FAO Irrigação e Drenagem, 48.

RICHARDS, L. A. Diagnóstico y Rehabilitación de Suelos Salinos y Sódicos. Editorial Limusa. México, 1974.

SCOFIELD, C. S. The Salinity of Irrigation Water. Smithan. Inst. Ann. Rpt. 1935: 275287 , illus.

STAMETS, P. \& CHILTON, J.S. The mushroom cultivator. Washington: Agrikon Press, 1983. 415p.

STANGHELLINI, C. Evapotranspiration in greenhouse with special reference to Mediterranean conditions. Acta Horticulture, Leven, n.335, p.296-304, 1993.

STEWART, D. P. C. Unburnt bush fallows: a preliminary investigation of soil conditions in a bush fallow and two sucessive crops of taro (Colocasia esculenta (L.) Schoot) in western Samoa. Field Crops Research, v.38, p.29-36, 1994.

TANAKA, M.; GENTA, H. Control Del Medio Ambiente Bajo Invernadero y Tunel Plástico. Salto, Uruguay. Estación Experimental de Citricultura, 1982. 61p. 